\title{
Acute Superoxide Radical Scavenging Reduces Blood Pressure but Does Not Influence Kidney Function in Hypertensive Rats with Postischemic Kidney Injury
}

\author{
Zoran Miloradović, ${ }^{1}$ Milan Ivanov, ${ }^{1}$ Nevena Mihailović-Stanojević, ${ }^{1}$ \\ Jelica Grujić Milanović, ${ }^{1}$ Đurđica Jovović, ${ }^{1}$ \\ Una-Jovana Vajić, ${ }^{1}$ and Jasmina Marković-Lipkovski ${ }^{2}$ \\ ${ }^{1}$ Department of Cardiovascular Physiology, Institute for Medical Research, University of Belgrade, 11129 Belgrade, Serbia \\ ${ }^{2}$ Institute of Pathology, Medical School, University of Belgrade, 11129 Belgrade, Serbia \\ Correspondence should be addressed to Milan Ivanov; ivmilan@imi.bg.ac.rs
}

Received 4 February 2014; Revised 16 May 2014; Accepted 19 May 2014; Published 22 June 2014

Academic Editor: Emmanuel A. Burdmann

\begin{abstract}
Copyright (C) 2014 Zoran Miloradović et al. This is an open access article distributed under the Creative Commons Attribution License, which permits unrestricted use, distribution, and reproduction in any medium, provided the original work is properly cited.
\end{abstract}

\begin{abstract}
Acute kidney injury (AKI) is associated with significant morbidity and mortality in hypertensive surroundings. We investigated superoxide radical molecules influence on systemic haemodynamic and kidney function in spontaneously hypertensive rats (SHR) with induced postischemic AKI. Experiment was performed in anesthetized adult male SHR. The right kidney was removed, and left renal artery was subjected to ischemia by clamping for 40 minutes. The treated group received synthetic superoxide dismutase mimetic TEMPOL in the femoral vein 5 minutes before, during, and 175 minutes after the period of reperfusion, while the control AKI group received the vehicle via the same route. All parameters were measured $24 \mathrm{~h}$ after renal reperfusion. TEMPOL treatment significantly decreased mean arterial pressure and total peripheral resistance $(P<0.05)$ compared to AKI control. It also increased cardiac output and catalase activity $(P<0.05)$. Lipid peroxidation and renal vascular resistance were decreased in TEMPOL $(P<0.05)$. Plasma creatinine and kidney morphological parameters were unchanged among TEMPOL treated and control groups. Our study shows that superoxide radicals participate in haemodynamic control, but acute superoxide scavenging is ineffective in glomerular and tubular improvement, probably due to hypertension-induced strong endothelial dysfunction which neutralizes beneficial effects of $\mathrm{O}_{2}^{-}$scavenging.
\end{abstract}

\section{Introduction}

Acute kidney injury (AKI), commonly caused by an obstruction of renal blood flow (renal ischemia) and characterized by a rapid decline in glomerular filtration rate (GFR) [1], is frequently associated with significant morbidity and mortality, the latter in the range of 30-60\%, depending on the clinical setting and presence or absence of nonrenal organ failure [2]. Unfortunately, therapeutic approaches to prevent or treat ARF are extremely limited, as the majority of interventional trials in AKI have failed in humans $[3,4]$. Therefore, the search for novel therapeutic modalities to prevent or treat AKI represents an area of intense investigation.

There are several factors involved in the initiation and maintenance of the AKI: decrease of glomerular capillary permeability, backleak of glomerular filtrate, tubular obstruction, and intrarenal vasoconstriction [1], but their causality has never been selective or rarely preventable. On the other hand, long-lasting hypertension damages medium-size and small-size renal blood vessels, disables adequate tubuloglomerular responses, and predisposes nephroangiosclerosis patients to AKI [5]. Also, patients with preexisting 
hypertension are at a particular risk of fatal outcome during AKI $[6,7]$.

Oxidative stress appears as a main mechanism causing tissue ischemia-reperfusion injury. Reperfusion injury generates a significant amount of free reactive oxygen species (ROS), the effect of which could not be "buffered" by endothelial cells exposed to ischemia [8]. Many studies have shown that ROS could induce lipid peroxidation, increase plasma membrane permeability [9], modulate both enzyme and membrane pump activity [10], and induce damage of DNA molecule [11, 12]. Study of Paller [13] has shown that antioxidants, including allopurinol, exert protective effects on postischemic kidney in rats, dogs, mice, rabbits, and pigs. On the other hand, study of Scaduto et al. [14] showed that allopurinol is ineffective in ischemic model of AKI. There are controversies related to efficacy of other antioxidative molecules in ischemic injury. Glutathione, normally present in tubulocites, expresses antioxidative properties, but its concentration markedly drops after renal ischemia [15]. Besides, glutathione therapy has shown opposite effects in ischemiareperfusion injury $[16,17]$.

Therefore, in the present study, by using oxidative scavenging therapy, we sought to determine whether superoxide radical molecules influence haemodynamic, lipid peroxidation and kidney function in spontaneously hypertensive rats (SHR) with induced postischemic AKI.

\section{Materials and Methods}

Male adults SHR, 24 weeks old, weighing about $300 \mathrm{~g}$, were bred in the Institute for Medical Research, Belgrade, Serbia, and fed with a standard chow for laboratory rats (Veterinarski Zavod, Subotica, Serbia).

All animal experiments were conducted in accordance with local institutional guidelines for the care and use of laboratory animals. The investigation also conformed to the principles and guidelines of Conseil de l'Europe (published in the Official Daily N. L358/1-358/6, 18 December, 1986), the US National Institutes of Health (Guide for the Care and Use of Laboratory Animals, NIH publication number 85-23), and the Canadian Council on Animal Care (CCAC).

2.1. Experimental Protocol. All experiments were performed in anaesthetized $(35 \mathrm{mg} / \mathrm{kg}$ b.m. sodium pentobarbital; intraperitoneal (i.p.)) rats.

2.2. Experimental Groups and Design. Hypertension was confirmed in all rats by indirect measurement on tail artery (Narco Bio Systems Inc., Houston, TX, USA), and the animals were divided into the following experimental groups: sham operated rats (SHAM); rats with induced postischemic AKI (AKI control); group AKI + TEMPOL, which received superoxide dismutase (SOD) mimetic TEMPOL (4-hydroxy2,2, 6,6-tetramethylpiperidine-1- ${ }^{15} \mathrm{~N}$-oxyl; Sigma Chemical Co., USA) during ARF induction.

AKI was induced by surgical removal of right kidney followed by atraumatic clamp occlusion of the left renal artery for 40 minutes. Control rats received vehicle (saline), while
AKI + TEMPOL group received SOD mimetic TEMPOL $(40 \mathrm{mg} / \mathrm{kg} / \mathrm{h}$ b.w.), in the femoral vein 5 minutes before and 175 minutes after the clamp removal. After infusion, the wound abdominal incision was surgically closed and SHR were placed individually into metabolic cages for 24 hours, with free access to water and chow.

\subsection{Haemodynamic Measurements 24 Hours after Reperfu-} sion. Haemodynamic parameters were measured in anaesthetized rats, through a femoral artery catheter (PE-50, ClayAdams Parsippany, NY, USA), connected to a physiological data acquisition system (9800TCR Cardiomax III-TCR, Columbus, OH, USA). A jugular vein was cannulated with polyethylene tubing PE-50 for the injection of cold saline. The left carotid artery was catheterized with PE-50 tubing and attached to a Thermo Sensor, which was coupled to the Cardiomax III for the determination of cardiac output (CO). The other end of thermocouple was placed in cold saline. Following $20 \mathrm{~min}$ for stabilization after surgery, cold saline $(0.2 \mathrm{~mL})$ was supplied through the jugular vein and mean arterial pressure (MAP), heart rate (HR), and CO were recorded. Total peripheral vascular resistance (TPVR) was calculated from MAP and CO (assuming that mean right atrial pressure is zero) and expressed as $\mathrm{mmHg} \operatorname{min~} \mathrm{kg} / \mathrm{mL}$.

After abdominal incision, left renal artery preparation was utilized and an ultrasonic flow probe (1RB, internal diameter $=1 \mathrm{~mm}$ ) was placed around the artery for the measurement of renal blood flow (RBF), using a Transonic T106 Small Animal Flowmeter (Transonic System Inc., Ithaca, NY, USA). Vascular resistance in renal artery (RVR) was calculated by dividing MAP by RBF, normalized for the body weight and expressed as $\mathrm{mmHg} \times \min \times \mathrm{kg} / \mathrm{mL}$.

2.4. Biochemical Measurements $24 \mathrm{~h}$ after Reperfusion. After haemodynamic studies, blood samples were taken for determination of creatinine $\left(\mathrm{P}_{\mathrm{Cr}}\right)$ and urea $\left(\mathrm{P}_{U}\right)$ in plasma. Lithium-heparin (Li-heparin, Sigma, USA) was used as an anticoagulant. $24 \mathrm{~h}$ urine samples were used for determination of urine creatinine $\left(\mathrm{U}_{\mathrm{Cr}}\right)$ and urea $\left(\mathrm{U}_{\mathrm{U}}\right)$ concentrations in urine. All biochemical parameters were measured using an automatic COBAS INTEGRA 400 plus (Hoffmann-La Roche, Germany) analyzer. Creatinine $\left(\mathrm{C}_{\mathrm{Cr}}\right)$ and urea $\left(\mathrm{C}_{\mathrm{U}}\right)$ clearances were calculated according to standard formula and normalized to body weight. After blood samples collection, animals were sacrificed by pentobarbital overdose injection.

Further, blood samples were centrifuged at $3000 \mathrm{rpm}$ at $4^{\circ} \mathrm{C}$ for 15 minutes and erythrocytes were separated. Hemoglobin $(\mathrm{Hb})$ content was estimated by the method of Drabkin and Austin [17]. Spectrophotometric analyses of plasma or erythrocytes were performed in Ultrospec 3300 pro UV/Visible spectrophotometer, Amersham Biosciences Corp., USA.

Activity of catalase (CAT) in erythrocytes was determined according to the procedure of Beutler [18] by following the absorbance of hydrogen peroxide at $230 \mathrm{~nm}$. The activity of this enzyme was expressed as unit per gram of hemoglobin $(\mathrm{U} / \mathrm{g} \mathrm{Hg})$ where one unit of CAT activity was defined as mmol of $\mathrm{H}_{2} \mathrm{O}_{2}$ per minute per gram of hemoglobin. 


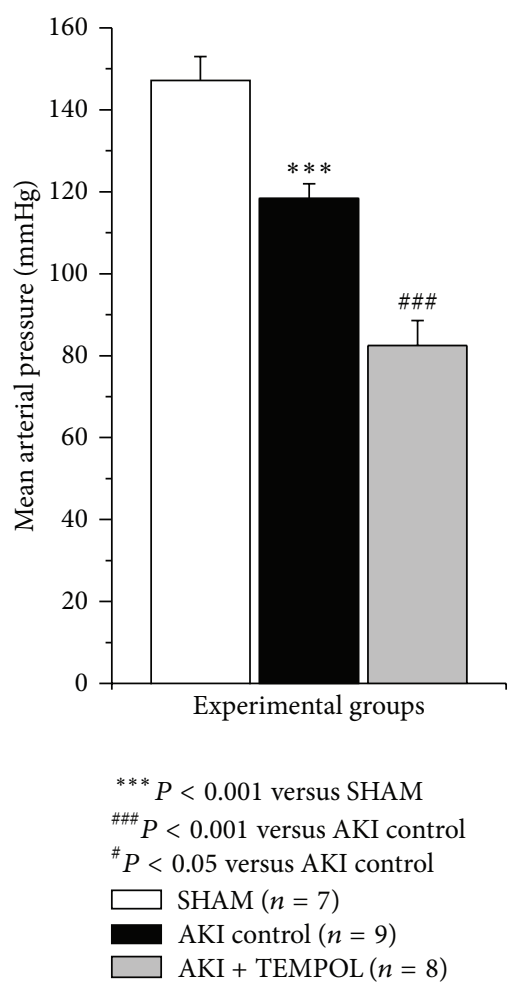

(a)

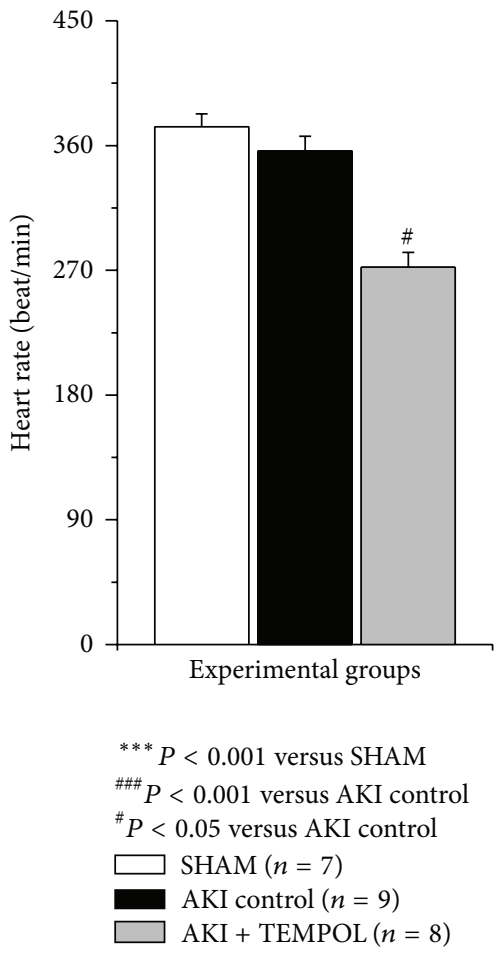

(b)

FIGURE 1: Mean arterial pressure and heart rate in experimental group 24 hours after reperfusion.

Thiobarbituric acid reactive substances (TBARS), as a marker of lipid peroxidation, were measured by using 2thiobarbituric acid (2,6-dihydroxypyrimidine-2-thiol; TBA). An extinction coefficient of $156000 \mathrm{M}-1 \mathrm{~cm}-1$ was used for calculation [19] and level of TBARS was expressed as nmol per milliliter of plasma.

2.5. Histological Examination. For determination of morphological changes, the left kidney was removed immediately after sacrificing and than prepared for light microscopy. The renal tissue was fixed in $10 \%$ buffered formalin solution. Later, the kidney was dehydrated in alcohol and blocked in paraffin wax, and $5 \mu \mathrm{m}$ thick sections were sliced and stained by periodic acid-Schiff (PAS) reaction. By light microscopy the following parameters were semiquantitatively evaluated on the scale from 0 to 4 according to the degree of lesions: intensity and spread of tubular necrosis, number of intraluminal cast formations, swelling and vacuolization of cells, loss of luminal membrane or brush borders, tubular dilatation, interstitial oedema, and separation of cells from tubular basal membrane. The severity of congestion, that is, the accumulation of red blood cells in glomeruli, peritubular capillaries, and intrarenal veins, was graded on a scale from 1 to 3, as described by Mandal et al. [20]. The sum of these changes represented the histopathological score for comparison between groups. Two independent investigators made histological evaluations; consensus was reached by discussion, whereas for the pathohistological score the mean value was calculated for each group.

2.6. Statistical Analysis. The results are expressed as mean \pm SEM. For results processing, we used the single-sided Student's $t$-test for two samples of equal variance (Microsoft Excel 2010). This test was used for comparing AKI control and SHAM, as well as AKI + TEMPOL and AKI control groups. $P$ values $<0.05$ were considered significant.

\section{Results}

3.1. Haemodynamic Measurements. Both MAP and HR were reduced in TEMPOL treated animals in comparison to AKI control $(P<0.001$ and $P<0.05$; Figure 1$)$. Furthermore, TPVR was significantly decreased $(P<0.05)$ and CO was significantly increased in SOD mimetic treated group versus control $(P<0.05)$ (Figure 2$)$.

AKI induction significantly reduced RBF and increased RVR in comparison to sham operated animals. TEMPOL infusion significantly increased RBF and reduced RVR $(P<$ $0.05)$ in AKI + TEMPOL group in comparison to AKI control (Figure 3).

3.2. Biochemical Parameters. After AKI induction plasma creatinine was significantly increased in AKI control group as compared to sham operated animals $(P<0.001)$. TEMPOL 


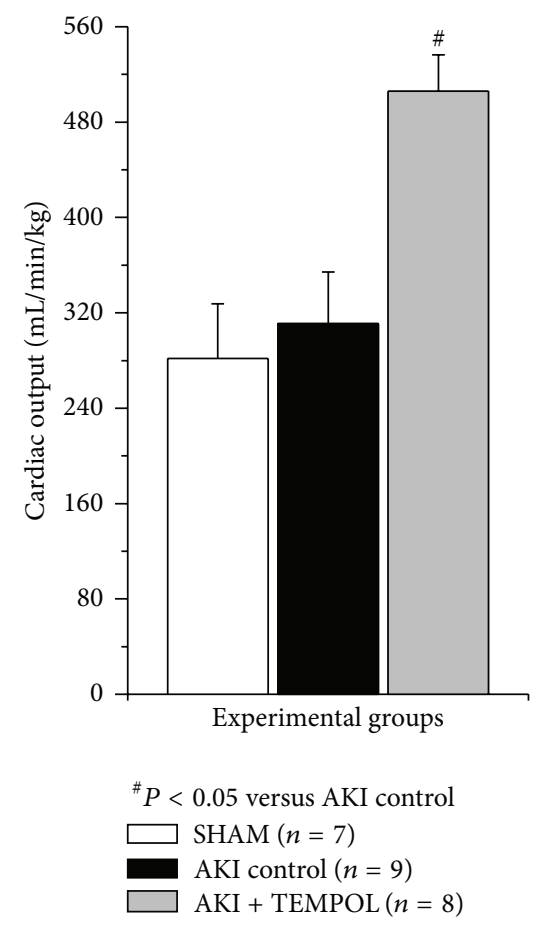

(a)

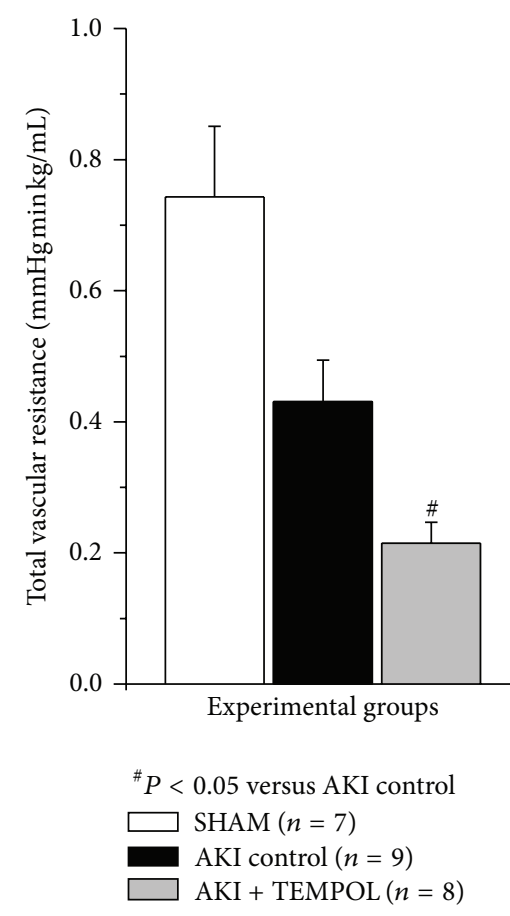

(b)

FIGURE 2: Cardiac output and total vascular resistance in experimental group 24 hours after reperfusion.

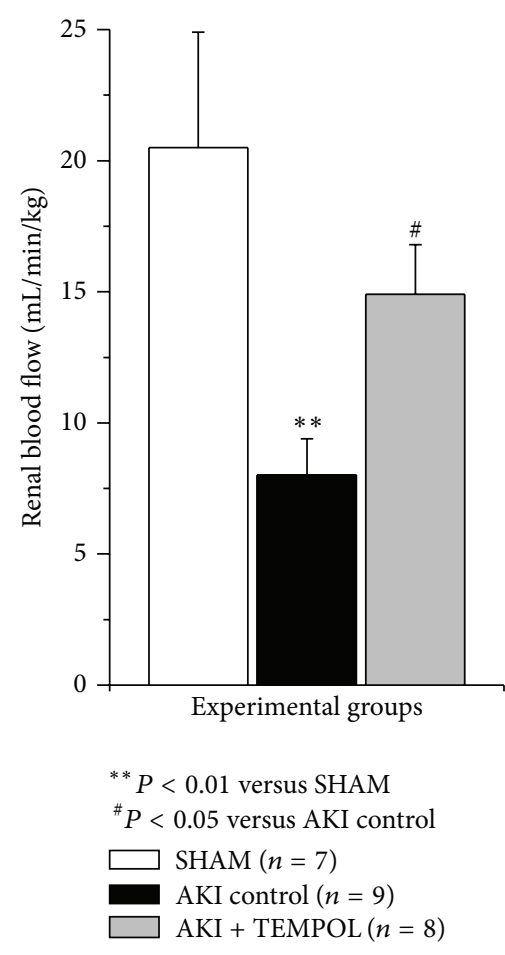

(a)

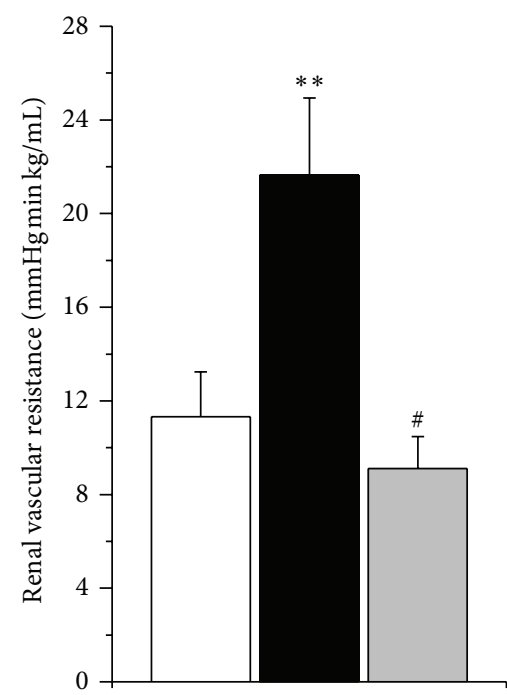

Experimental groups

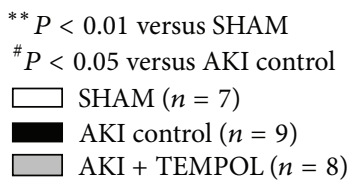

(b)

FIGURE 3: Renal blood flow and renal vascular resistance in experimental group 24 hours after reperfusion. 
TABLE 1: Biochemical parameters in experimental groups 24 hours after reperfusion.

\begin{tabular}{|c|c|c|c|c|c|c|c|}
\hline & $\begin{array}{l}\text { Plasma creatinine } \\
(\mu \mathrm{mol} / \mathrm{L})\end{array}$ & $\begin{array}{l}\text { Plasma urea } \\
(\mathrm{mmol} / \mathrm{L})\end{array}$ & $\begin{array}{c}\text { Creatinine } \\
\text { clearance } \\
(\mathrm{mL} / \mathrm{min} / \mathrm{kg})\end{array}$ & $\begin{array}{l}\text { Urea clearance } \\
(\mathrm{mL} / \mathrm{min} / \mathrm{kg})\end{array}$ & $\begin{array}{c}\text { Plasma } \\
\text { phosphates } \\
(\mathrm{mmol} / \mathrm{L})\end{array}$ & $\begin{array}{c}\text { Catalase activity } \\
(\mathrm{U} / \mathrm{g} \mathrm{Hb})\end{array}$ & $\begin{array}{c}\text { TBARS } \\
(\mathrm{nmol} / \mathrm{mL})\end{array}$ \\
\hline $\begin{array}{l}\text { SHAM } \\
(n=7)\end{array}$ & $32.71 \pm 3.94$ & $12.37 \pm 1.70$ & $6.50 \pm 0.99$ & $2.38 \pm 0.28$ & $2.39 \pm 0.39$ & $22.15 \pm 6.05$ & $7.28 \pm 0.76$ \\
\hline $\begin{array}{l}\text { AKI control } \\
(n=9)\end{array}$ & $242.71 \pm 20.24^{* * *}$ & $61.90 \pm 3.93^{* * *}$ & $0.29 \pm 0.13^{* * *}$ & $0.11 \pm 0.04^{* * *}$ & $5.57 \pm 0.61^{* * *}$ & $14.32 \pm 2.91$ & $10.54 \pm 0.92^{* *}$ \\
\hline $\begin{array}{l}\text { AKI + TEMPOL } \\
(n=8)\end{array}$ & $225.63 \pm 22$ & $57.36 \pm 3.17$ & $0.32 \pm 0.06$ & $0.11 \pm 0.02$ & $4.25 \pm 0.60$ & $27.57 \pm 6.36^{\#}$ & $7.24 \pm 0.37^{\# \#}$ \\
\hline
\end{tabular}

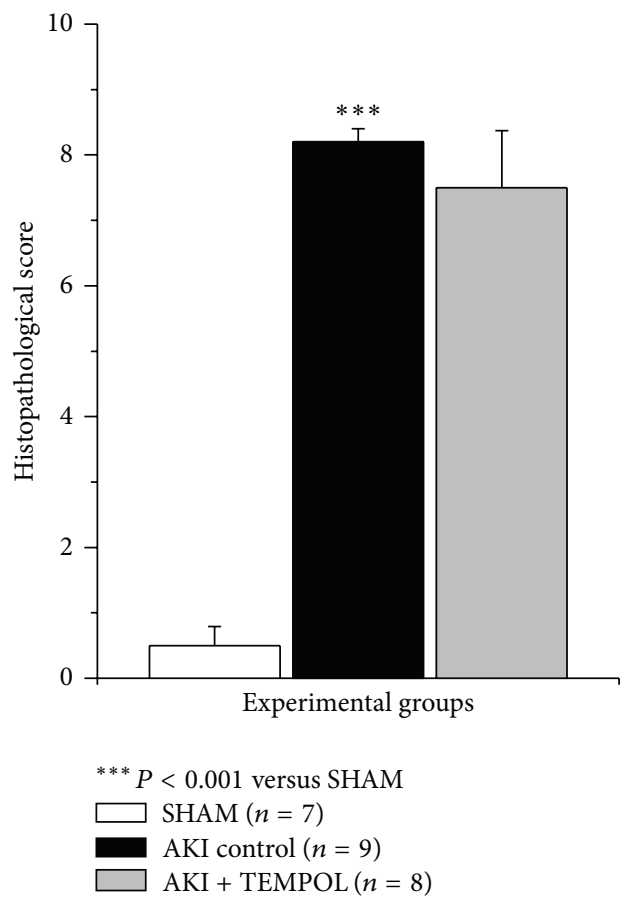

FIGURE 4: Histopathological score in experimental group 24 hours after reperfusion.

treatment had no influence on this glomerular filtration marker. Also, TEMPOL infusion changed neither $\mathrm{Pu}$ nor Pphos levels in postischemic SHR (Table 1). Similar relation was observed in both clearances. AKI induction significantly reduced $\mathrm{C}_{\mathrm{Cr}}$ and $\mathrm{C}_{\mathrm{U}}$, while TEMPOL treatment had no influence on glomerular filtration improvement (Table 1).

Enzyme catalase activity dropped after AKI induction, while TEMPOL treatment significantly elevated its activity $(P<0.05) 24$ hours after ischemia (Table 1$)$.

TBARS level was significantly increased in AKI group. TEMPOL treatment significantly reduced lipid peroxidation $(P<0.01)$ (Table 1$)$.

3.3. Histological Studies. Histological examination of the kidney specimens obtained 24 hours after AKI revealed that rats treated with TEMPOL had minor morphological changes in comparison to AKI control group (Figure 4).
Figure 5(a) shows the normal appearance of glomeruli, interstitium, tubules, and blood vessels in SHAM operated animals. Only in a few kidney specimens were observed a less number of PAS positive casts in the tubular lumen.

The kidneys of animals with AKI showed dilatation of certain segments of the proximal and distal tubules, with or without loss of brush border. The most notable changes were present in the corticomedullary zone where the broad areas of necrosis of tubules and a large number of PAS positive casts in the collecting ducts were observed. The intensity of interstitial edema in this group varies from sample to sample (Figure 5(b)).

In TEMPOL treated animals, similar damage is noticed in comparison to kidneys of control AKI animals. Tubular dilatation is noticeable. In the corticomedullary zone, tubular necrosis is slightly reduced and infarct fields have similar intensity as AKI control animals. Interstitial edema is observed. In addition, the number of tubular casts in the renal medulla is comparable to AKI control animals (Figure 5(c)).

\section{Discussion}

In this study we examined the role of ROS in experimental genetically induced hypertension during postischemic AKI development. After AKI induction we noticed both mild MAP and HR reduction, similar to the results of Bowmer et al. [21] performed in the model of glycerol induced AKI. These authors considered high uremia (plasma urea was significantly elevated in AKI group in our study as well) influence on autonomic nervous system (diminished $\alpha_{1}$ adrenoreceptors sensitivity) as a cause of both MAP and $\mathrm{HR}$ reduction after AKI. Many studies have shown that superoxide radical scavenging reduces blood pressure in SHR [22-24]. Nishiyama et al. [25] have shown reduction of both blood pressure and TPVR due to $\mathrm{O}_{2}{ }^{-}$scavenging in Ang II induced hypertension. In our experimental setting, TEMPOL treatment resulted in blood pressure lowering, followed by $\mathrm{CO}$ increasing and concomitant TPVR reduction in comparison to control AKI animals. Considering these results, it is reasonable to conclude that $\mathrm{O}_{2}{ }^{-}$generation affects blood pressure regulation in the presented postischemic kidney hypertensive model.

Renal vasoconstriction is one of the major pathogenetic mechanisms of AKI development; therefore control of 


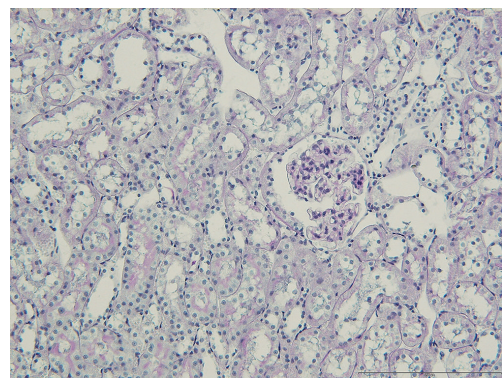

(a)

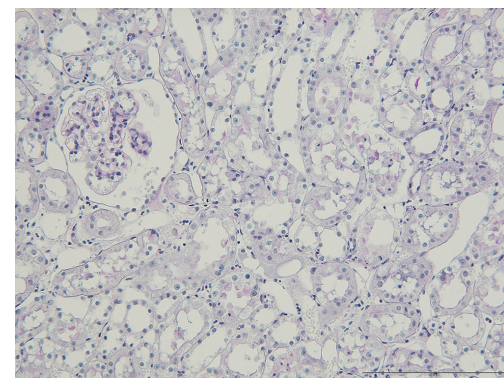

(b)

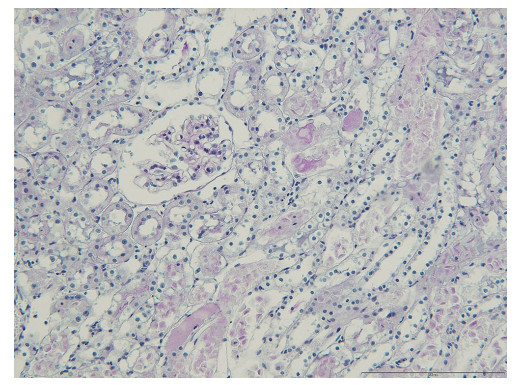

(c)

FIGURE 5: (a) Normal appearance of glomeruli, interstitium, tubules, and blood vessels in SHAM operated animals. Very rare PAS positive casts in the lumen of the tubules. (b) Massive corticomedullary tubular necrosis (solid arrow). Intensive interstitial edema. Numerous PAS positive casts in the collecting ducts and dilatation of certain segments (dash arrow) of the proximal and distal tubules (with or without loss of brush border) in AKI control group. (c) AKI + TEMPOL group. Noticeable tubular dilatation. Slightly reduced tubular necrosis in the corticomedullary zone, with interstitial edema. Tubular casts in the renal medulla is comparable to AKI control animals.

the renal haemodynamic is essential for this disorder. Schnackenberg et al. [22] have shown that TEMPOL $(12.4 \mathrm{mg} / \mathrm{kg}$ t.m.) significantly reduced RVR without influencing RBF in SHR. Also, study of de Richelieu [26] showed chronic treatment with TEMPOL ( $1 \mathrm{mM}, 15$ days) towards effective RVR reduction in SHR. Furthermore, Li et al. [27] suggest that TEMPOL normalizes the RBF in SHR. Results of our study are in accordance with these studies, indicating that ROS scavenging is beneficial in reduction of postischemic induced renal vasoconstriction in SHR. Majid and Kopkan [28] showed that TEMPOL increased blood flow after angiotensin II induced oxidative stress in hypertensive rats. It is well known that postischemic AKI induces massive production of $\mathrm{O}_{2}{ }^{-}$radicals [29], which have important role in human and animal hypertension [30-35]. Besides, there is increased production of NADPH oxidase iRNA in renal tissue of SHR, which is responsible for $\mathrm{O}_{2}{ }^{-}$generation [35]. Cai and Harrison showed [36] that overproduction of $\mathrm{O}_{2}{ }^{-}$is closely related to endothelial dysfunction and vasoconstriction. Therefore, we can conclude that, in our experimental model, both blood pressure lowering and renal artery vasodilatation in TEMPOL treated animals are mainly due to $\mathrm{O}_{2}{ }^{-}$scavenging.

In the present study, there was a sevenfold increase of both plasma creatinine and urea and otherwise dramatically dropping of creatinine and urea clearance after AKI induction. The former indicates detrimental glomerular filtration after ischemia-reperfusion injury. TEMPOL treatment did not affect these parameters of kidney function. Chatterjee [37] reported plasma creatinine lowering due to TEMPOL treatment after kidney injury in Wistar rats. By our opinion, discrepancies among these studies could be explained by hypertensive postischemic milieu in SHR, which causes strong renal endothelial dysfunction and therefore abolishes positive effects of $\mathrm{O}_{2}{ }^{-}$scavenging 24 hours after reperfusion. Hyperphosphatemia frequently occurs after AKI, due to diminished expression of tubular sodium dependent phosphate cotransporter [38]. In our experimental model,
TEMPOL treatment did not change phosphatemia, indicating $\mathrm{O}_{2}{ }^{-}$scavenging ineffective in tubular injury amelioration. This observation was confirmed by morphologically unchanged tubular structure in AKI + TEMPOL group, in comparison to AKI control. There is evidence that ischemiareperfusion injury results in decreased erythrocyte catalase activity [39], what is also noticed in our experimental study. Hence, TEMPOL treatment induced twofold increasing of CAT activity; this should diminish oxidative stress during postischemic AKI development in our study. Besides, Yuan et al. [40] showed CAT activity positively correlated with elevated antioxidant superoxide dismutase enzyme. Another study [41] showed CAT mimetic property of TEMPOL. On the other hand, lipid peroxidation is closely related to cell structure damage. There were many studies showing elevated lipid peroxidation in plasma, erythrocytes, and kidney tissue, after renal ischemia [13,42, 43]. TEMPOL treatment in our hypertensive rats decreased plasma lipid peroxidation which correlates with results of Zhang et al. [44]. They showed TEMPOL $(10 \mathrm{mg} / \mathrm{kg}$ and $30 \mathrm{mg} / \mathrm{kg}$ b.w.) effective in TBARS lowering at Sprague-Dawley Ang II hypertensive rats. Considering that $\mathrm{NAD}(\mathrm{P}) \mathrm{H}$ oxidase is one of the main sources generating ROS [45] and that superoxide scavenging in our study resulted in both CAT activity increasing and lipid peroxidation decreasing, we could be free to conclude that TEMPOL treatment probably diminished activity of NADPH oxidase as well. Our results show that morphological changes in the kidney of TEMPOL treated animals were similar to control AKI rats. Although some data [37] showed TEMPOL treatment successful against postischemic kidney injury in normotensive conditions, our results indicate that hypertensive milieu in the kidneys of SHR suppresses morphological renal recovery after superoxide radical scavenging.

Taken together, results of our study show that acute TEMPOL treatment can diminish hypertension and improve systemic haemodynamic parameters after postischemic renal injury, suggesting that postischemic induced superoxide anions at least in one part participate in blood pressure 
and haemodynamic control in this condition. On the other hand, presented results indicate that acute superoxide scavenging is ineffective in general kidney function improvement, despite renal haemodynamic improvement 24 hours after reperfusion. In our opinion, this is due to strong renal endothelial dysfunction induced by hypertension, which neutralizes beneficial effect of acute $\mathrm{O}_{2}{ }^{-}$scavenging. Thus, tubular injuries as main targets of postischemic episode remain mostly unaffected. Beyond this disappointment, there is a fact that TEMPOL treatment did not additionally decline glomerular function in postischemic SHR, so it could be effective in blood pressure therapy in hypertensive AKI patients. On the other hand, there are many open questions related to efficacy of long lasting TEMPOL treatment after postischemic kidney injury in hypertension or to protective influence of superoxide scavenging in recovery phase of AKI which could be topic for more complex studies.

\section{Conflict of Interests}

The authors declare that they have no conflict of interests.

\section{Acknowledgment}

This work was supported by a Grant (Project OI175096) from the Ministry of Education, Science and Technological development of Serbia.

\section{References}

[1] A. R. Nissenson, "Acute renal failure: definition and pathogenesis," Kidney International, Supplement, vol. 53, no. 66, pp. S7-S10, 1998.

[2] J. Purday, "Acute renal failure," in Oxford Handbook of Anaesthesia, K. G. Allman and I. H. Wilson, Eds., pp. 116-118, Oxford University Press, New York, NY, USA, 2001.

[3] R. L. Mehta, "Acute renal failure and cardiac surgery: marching in place or moving ahead?" Journal of the American Society of Nephrology, vol. 16, no. 1, pp. 12-14, 2005.

[4] T. Bove, G. Landoni, M. G. Calabrò et al., "Renoprotective action of fenoldopam in high-risk patients undergoing cardiac surgery: a prospective, double-blind, randomized clinical trial," Circulation, vol. 111, no. 24, pp. 3230-3235, 2005.

[5] W. J. Welch, A. Tojo, and C. S. Wilcox, "Roles of NO and oxygen radicals in tubuloglomerular feedback in SHR," The American Journal of Physiology-Renal Physiology, vol. 278, no. 5, pp. F769-F776, 2000.

[6] C. S. Rihal, S. C. Textor, D. E. Grill et al., "Incidence and prognostic importance of acute renal failure after percutaneous coronary intervention," Circulation, vol. 105, no. 19, pp. 22592264, 2002.

[7] S. Aronson and R. Blumenthal, "Perioperative renal dysfunction and cardiovascular anesthesia: concerns and controversies," Journal of Cardiothoracic and Vascular Anesthesia, vol. 12, no. 5, pp. 567-586, 1998.

[8] M. Radović, Z. Miloradović, T. Popović et al., "Allopurinol and enalapril failed to conserve urinary NOx and sodium in ischemic acute renal failure in spontaneously hypertensive rats," The American Journal of Nephrology, vol. 26, no. 4, pp. 388-399, 2006.
[9] H. Kappus, "Lipid peroxidation: mechanisms, analysis, enzymology and biological relevance," in Oxidative Stress, H. Sies, Ed., pp. 273-310, Academic Press, New York, NY, USA, 1985.

[10] K. Kato, M. Kato, T. Matsuoka, and A. Mustapha, "Depression of membrane-bound $\mathrm{Na}^{+}-\mathrm{K}^{+}$-ATPase activity induced by free radicals and by ischemia of kidney," The American Journal of Physiology-Cell Physiology, vol. 254, no. 2, pp. C330-C337, 1988.

[11] M. K. Brawn and I. Fridovich, "Increased superoxide radical production evokes inducible DNA repair in Escherichia coli," The Journal of Biological Chemistry, vol. 260, no. 2, pp. 922-925, 1985.

[12] A. B. Weitberg, S. A. Weitzman, E. P. Clark, and T. P. Stossel, "Effects of antioxidants on oxidant-induced sister chromatid exchange formation," Journal of Clinical Investigation, vol. 75, no. 6, pp. 1835-1841, 1985.

[13] M. S. Paller, "Free radical-mediated postischemic injury in renal transplantation," Renal Failure, vol. 14, no. 3, pp. 257-260, 1992.

[14] R. C. Scaduto Jr., V. H. Gattone II, L. W. Grotyohann, J. Wertz, and L. F. Martin, "Effect of an altered glutathione content on renal ischemic injury," The American Journal of PhysiologyRenal Fluid and Electrolyte Physiology, vol. 255, no. 5, pp. F911F921, 1988.

[15] M. S. Paller, "Renal work, glutathione and susceptibility to free radical-mediated postischemic injury," Kidney International, vol. 33, no. 4, pp. 843-849, 1988.

[16] H. C. Yang, V. H. Gattone II, L. F. Martin, L. W. Grotyohann, J. McElroy, and R. C. Scaduto Jr., "The effect of glutathione content on renal function following warm ischemia," Journal of Surgical Research, vol. 46, no. 6, pp. 633-636, 1989.

[17] D. Drabkin and H. Austin, "Spectrophotometric studies preparations from washed blood cells," The Journal of Biological Chemistry, vol. 112, pp. 51-65, 1935.

[18] E. Beutler, "Red cell metabolism, a manual of biochemical methods," in Catalase, E. Beutler, Ed., pp. 105-106, Grune and Stratton, New York, NY, USA, 1982.

[19] H. Ohkawa, N. Ohishi, and K. Yagi, "Assay for lipid peroxides in animal tissues by thiobarbituric acid reaction," Analytical Biochemistry, vol. 95, no. 2, pp. 351-358, 1979.

[20] A. K. Mandal, C. C. Haygood, R. D. Bell et al., "Effects of acute and chronic splenectomy on experimental acute renal tubular lesions," Journal of Laboratory and Clinical Medicine, vol. 92, no. 5, pp. 698-711, 1978.

[21] C. J. Bowmer, A. J. Nichols, M. Warren, and M. S. Yates, "Cardiovascular responses in rats with glycerol-induced acute renal failure," The British Journal of Pharmacology, vol. 79, no. 2, pp. 471-476, 1983.

[22] C. G. Schnackenberg, W. J. Welch, and C. S. Wilcox, "Normalization of blood pressure and renal vascular resistance in shr with a membrane-permeable superoxide dismutase mimetic role of nitric oxide," Hypertension, vol. 32, no. 1, pp. 59-64, 1998.

[23] M. Yoshioka, K. Aoyama, and T. Matsushita, "Effects of ascorbic acid on blood pressure and ascorbic acid metabolism in spontaneously hypertensive rats (SH rats)," International Journal for Vitamin and Nutrition Research, vol. 55, no. 3, pp. 301-307, 1985.

[24] K. Nakazono, N. Watanabe, K. Matsuno, J. Sasaki, T. Sato, and M. Inoue, "Does superoxide underlie the pathogenesis of hypertension?" Proceedings of the National Academy of Sciences of the United States of America, vol. 88, no. 22, pp. 10045-10048, 1991. 
[25] A. Nishiyama, T. Fukui, Y. Fujisawa et al., "Systemic and regional hemodynamic responses to tempol in angiotensin II-infused hypertensive rats," Hypertension, vol. 37, no. 1, pp. 77-83, 2001.

[26] L. T. de Richelieu, C. M. Sorensen, N. Holstein-Rathlou, and M. Salomonsson, "NO-independent mechanism mediates tempolinduced renal vasodilation in SHR," The American Journal of Physiology-Renal Physiology, vol. 289, no. 6, pp. F1227-F1234, 2005.

[27] L. Li, B. S. Y. Li, P. Storey, L. Fogelson, W. Li, and P. Prasad, "Effect of free radical scavenger (tempol) on intrarenal oxygenation in hypertensive rats as evaluated by BOLD MRI," Journal of Magnetic Resonance Imaging, vol. 21, no. 3, pp. 245-248, 2005.

[28] D. S. A. Majid and L. Kopkan, "Nitric oxide and superoxide interactions in the kidney and their implication in the development of salt-sensitive hypertension," Clinical and Experimental Pharmacology and Physiology, vol. 34, no. 9, pp. 946-952, 2007.

[29] M. S. Paller, J. R. Hoidal, and T. F. Ferris, "Oxygen free radicals in ischemic acute renal failure in the rat," Journal of Clinical Investigation, vol. 74, no. 4, pp. 1156-1164, 1984.

[30] S. Adler and H. Huang, "Impaired regulation of renal oxygen consumption in spontaneously hypertensive rats," Journal of the American Society of Nephrology, vol. 13, no. 7, pp. 1788-1794, 2002.

[31] A. D. Dobrian, S. D. Schriver, and R. L. Prewitt, "Role of angiotensin II and free radicals in blood pressure regulation in a rat model of renal hypertension," Hypertension, vol. 38 , no. 3 , pp. 361-366, 2001.

[32] S. Kerr, M. J. Brosnan, M. McIntyre, J. L. Reid, A. F. Dominiczak, and C. A. Hamilton, "Superoxide anion production is increased in a model of genetic hypertension: role of the endothelium," Hypertension, vol. 33, no. 6, pp. 1353-1358, 1999.

[33] S. Meng, G. W. Cason, A. W. Gannon, L. C. Racusen, and R. D. Manning Jr., "Oxidative stress in Dahl salt-sensitive hypertension," Hypertension, vol. 41, no. 6, pp. 1346-1352, 2003.

[34] J. B. Park, R. M. Touyz, X. Chen, and E. L. Schiffrin, "Chronic treatment with a superoxide dismutase mimetic prevents vascular remodeling and progression of hypertension in salt-loaded stroke-prone spontaneously hypertensive rats," The American Journal of Hypertension, vol. 15, no. 1, pp. 78-84, 2002.

[35] C. Russo, O. Olivieri, D. Girelli et al., "Anti-oxidant status and lipid peroxidation in patients with essential hypertension," Journal of Hypertension, vol. 16, no. 9, pp. 1267-1271, 1998.

[36] H. Cai and D. G. Harrison, "Endothelial dysfunction in cardiovascular diseases: the role of oxidant stress," Circulation Research, vol. 87, no. 10, pp. 840-844, 2000.

[37] P. K. Chatterjee, S. Cuzzocrea, P. A. J. Brown et al., “Tempol, a membrane-permeable radical scavenger, reduces oxidant stress-mediated renal dysfunction and injury in the rat," Kidney International, vol. 58, no. 2, pp. 658-673, 2000.

[38] D. Rubinger, H. Wald, D. Gimelreich et al., "Regulation of the renal sodium-dependent phosphate cotransporter $\mathrm{NaPi} 2$ (Npt2) in acute renal failure due to ischemia and reperfusion," Nephron-Physiology, vol. 100, no. 1, pp. 1-12, 2005.

[39] M. Inal, M. Altinişik, and M. D. Bilgin, "The effect of quercetin on renal ischemia and reperfusion injury in the rat," Cell Biochemistry and Function, vol. 20, no. 4, pp. 291-296, 2002.

[40] Y. V. Yuan, D. D. Kitts, and D. V. Godin, "Heart and red blood cell antioxidant status and plasma lipid levels in the spontaneously hypertensive and normotensive Wistar-Kyoto rat," Canadian Journal of Physiology and Pharmacology, vol. 74, no. 3, pp. 290-297, 1996.
[41] M. C. Krishna, A. Samuni, J. Taira, S. Goldstein, J. B. Mitchell, and A. Russo, "Stimulation by nitroxides of catalase-like activity of hemeproteins. Kinetics and mechanism," The Journal of Biological Chemistry, vol. 271, no. 42, pp. 26018-26025, 1996.

[42] R. Campos, M. H. M. Shimizu, R. A. Volpini et al., "Nacetylcysteine prevents pulmonary edema and acute kidney injury in rats with sepsis submitted to mechanical ventilation," The American Journal of Physiology - Lung Cellular and Molecular Physiology, vol. 302, no. 7, pp. L640-L650, 2012.

[43] L. Lucchi, S. Bergamini, A. Iannone et al., "Erythrocyte susceptibility to oxidative stress in chronic renal failure patients under different substitutive treatments," Artificial Organs, vol. 29, no. 1, pp. 67-72, 2005.

[44] G. X. Zhang, S. Kimura, A. Nishiyama, T. Shokoji, M. Rahman, and Y. Abe, "ROS during the acute phase of Ang II hypertension participates in cardiovascular MAPK activation but not vasoconstriction," Hypertension, vol. 43, no. 1, pp. 117-124, 2004.

[45] T. M. Paravicini and R. M. Touyz, "Redox signaling in hypertension," Cardiovascular Research, vol. 71, no. 2, pp. 247-258, 2006. 


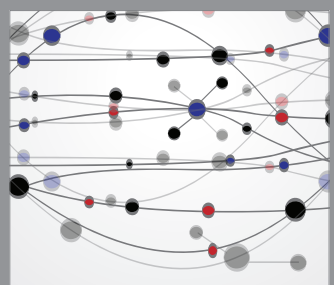

The Scientific World Journal
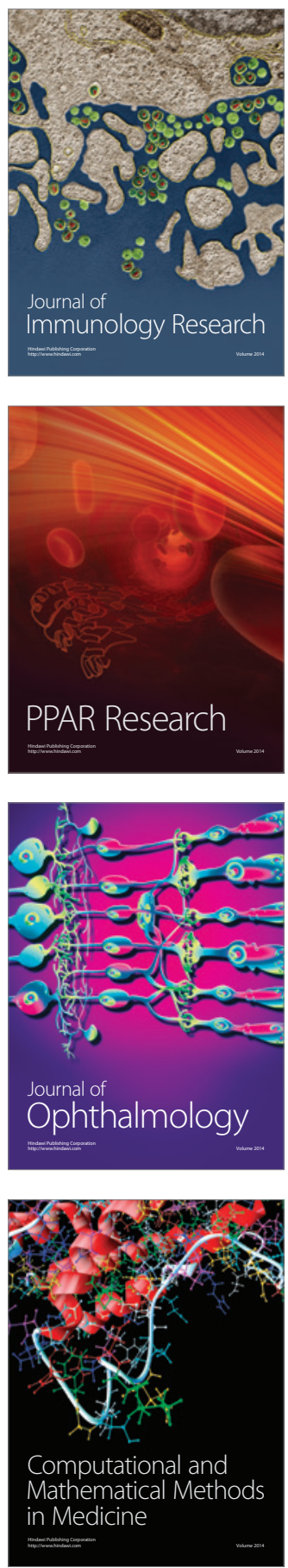

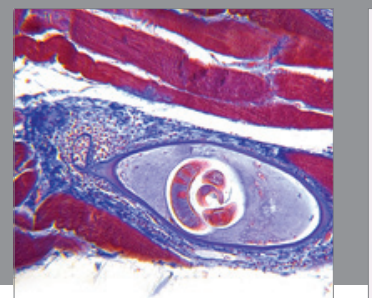

Gastroenterology

Research and Practice
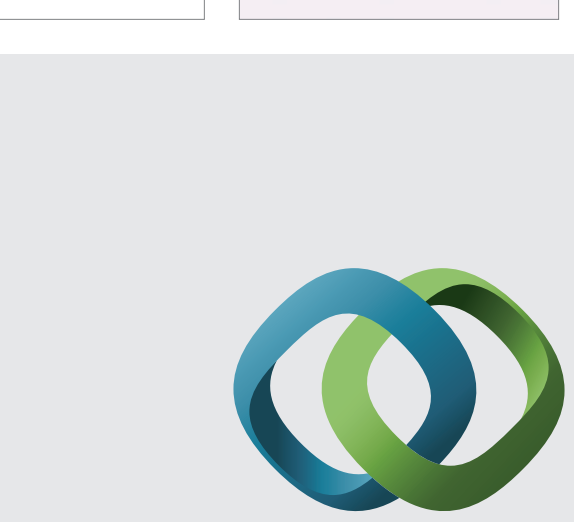

\section{Hindawi}

Submit your manuscripts at

http://www.hindawi.com
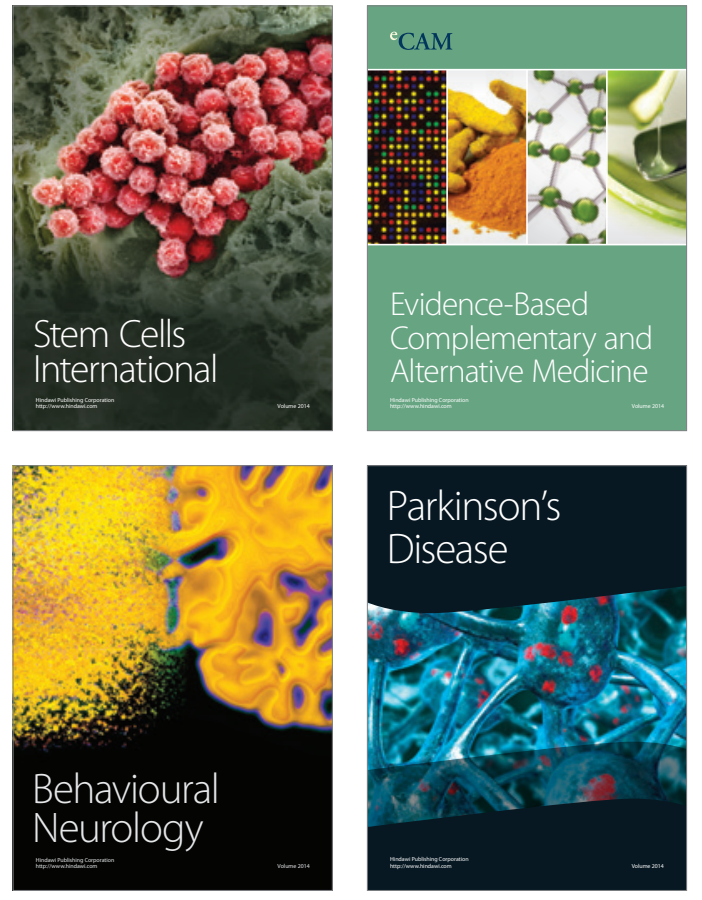
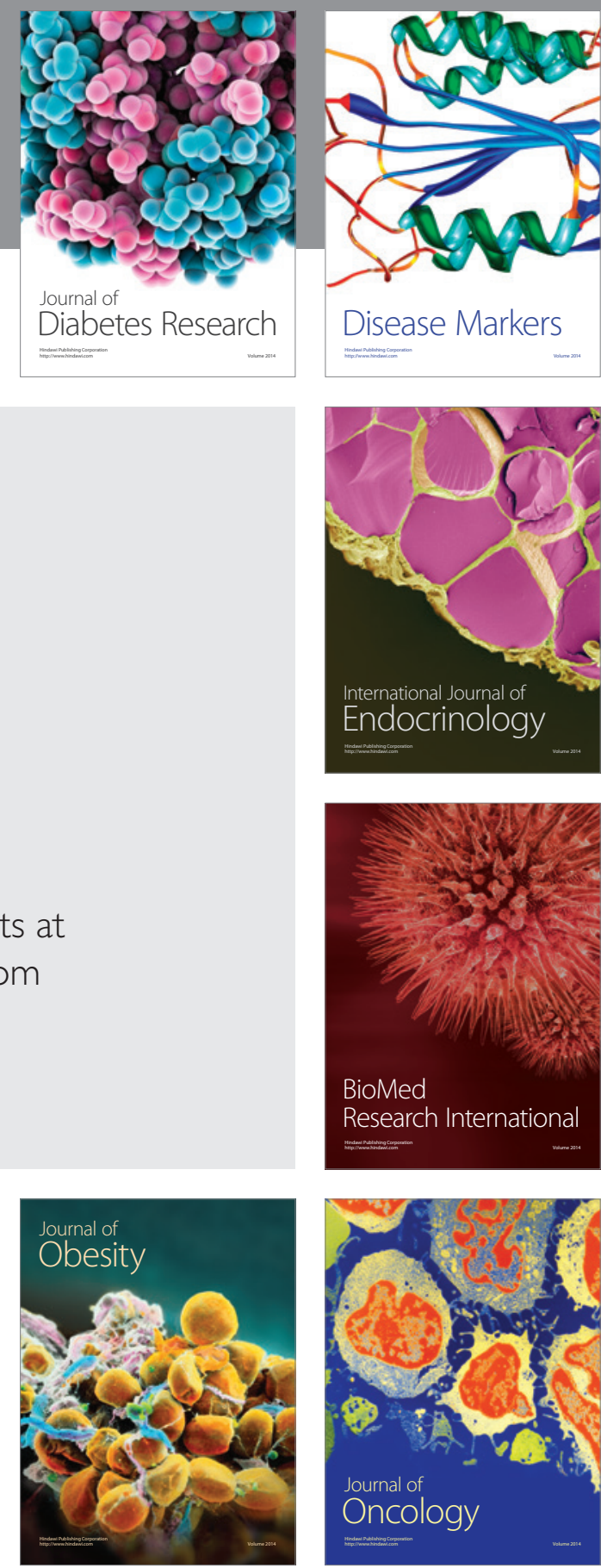

Disease Markers
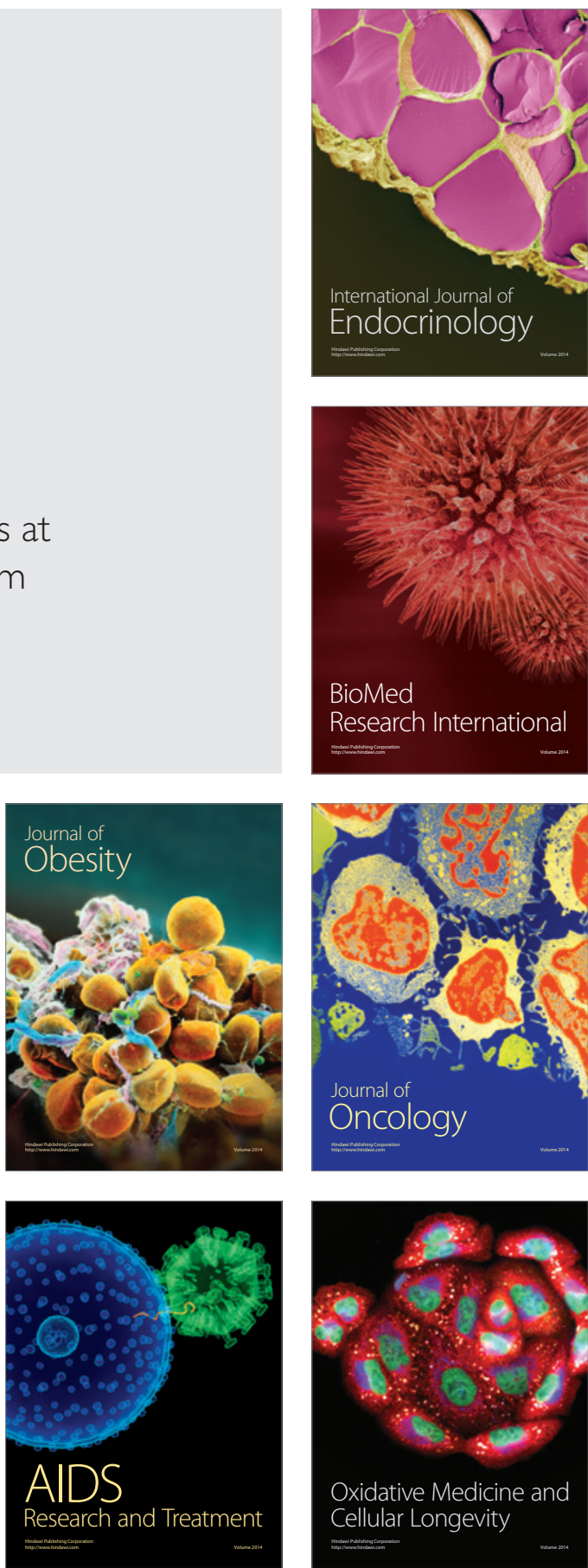